\title{
Penguatan Kewenangan DPD Dalam Sistem Ketatanegaraan Indonesia Pasca Putusan Mahkamah Konstitusi Nomor 92/PUU-X/2012
}

\author{
Abdul Hakim Siagian \\ Fakultas Hukum Universitas Muhammadiyah Sumatera Utara \\ Jl. Kapten Mukhtar Basri No. 3, Medan - Sumatera Utara, Indonesia \\ Telp: (061) 6622400, Fax: (061) 6623474, 6631003), Kode Pos 20238 \\ Email: abdulhakim@umsu.ac.id
}

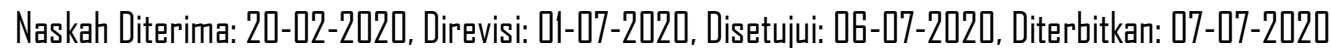
DDI: https://dai.org//0.30596/dll.vii2.4348
\end{abstract}

\begin{abstract}
Abstrak
Di dalam negara federal, sistem keterwakilan atas rakyatnya dibagi atas kamar (cameral). Dalam sistem pembagian kamar, DPR dan DPD mempunyai sistem yang biasa disebut checks and balances. Yang masing-masing kamar saling mengawasi dan mengimbangi kinerja, dalam artian DPD seharusnya mempunyai kewenangan yang sama dengan DPR dalam fungsi legislasi. Penelitian ini bertujuan untuk menggambarkan kewenangan DPD dan mengoptimalisasikan peran DPD dalam fungsi legislasi pasca Putusan Mahkamah Konstitusi Nomor 92/PUU-X/2012. Penelitian ini merupakan penelitian normatif yang bersumber dari buku-buku dan dokumen tentang DPD. Hasil penelitian ini menunjukan kewenangan DPD yang lemah karena masih dianggap sebagai co-legislator DPR dan bentuk optimalisasinya dapat dilakukan melalui cara amandemen kelima atau pembaharuan Undang-Undang pembentukan peraturan perundang-undangan dan UU MD3. Maka kelemahan DPD yang mengakibatkan lemahnya sistem checks and balances dalam parlemen harus dilakukan optimalisasi kewenangan DPD.
\end{abstract}

Kata Kunci: DPD, Fungsi, Kewenangan dan Penguatan.

\section{Abstract}

In a federal state, the system of representation of its people is divided into rooms (cameral). In the room division system, the DPR and DPD have a system commonly called checks and balances. Each of the chambers supervises and matches each other's performance, in the sense that the DPD should have the same authority as the DPR in the legislative function. This study aims to describe the authority of the DPD and optimize the role of the DPD in the legislative function after the Constitutional Court Ruling Number 92 / PUU-X/2012. This research is a normative research sourced from books and documents about DPD. The results of this study indicate that the DPD's authority is weak because it is still considered as a co-legislator of the $D P R$ and the form of its optimization can be done through the fifth amendment or the renewal of the Law forming legislation and the MD3 Law. Then the weakness of the DPD which results in a weak system of checks and balances in the parliament must be optimized DPD authority.

Keywords: DPD, Function, Authority and Strengthening. 


\section{PENDAHULUAN}

Perubahan Undang-Undang Dasar (UUD) 1945 yang dilakukan pada kurun waktu 19992002 (Amandemen pertama (19 oktober 1999), amandemen kedua (18 Agustus 2000), amandemen ketiga (9 November 2001), dan amandemen keempat (10 Agustus 2002). Dalam 4 tahun perubahan konstitusi semasa tahun 1999-2000 juga membawa dampak terhadap sistem kekuasaan legislatif, eksekutif, dan yudikatif yang merubah sistem ketatanegaraan di Indonesia. Telah membawa perubahan besar dalam sistem ketatanegaraan Indonesia, baik dalam kelembagaan kekuasaan legislatif, eksekutif, dan yudikatif. Salah satu perubahan penting dalam format ketatanegaraan Republik Indonesia pasca-amandemen ketiga UUD 1945 adalah dibentuknya lembaga-lembaga tinggi negara baru, antara lain Dewan Perwakilan Daerah (DPD) (A. Muin Fahmal, makalah "Konstitusionalitas DPD berdasarkan Pasal 22 D UUD NRI 1945 dan pada posisi DPD pada UU MD3 pasca-putusan MK). Komisi Yudisial (KY), dan Mahkamah Konstitusi (MK).

Sidang Tahunan Tahun 2001 pada pembahasan Amandemen Ketiga UUD 1945 dibahas pula keberadaan Komisi Yudisial. Pasal 24B UUD 1945 secara lugas menyebutkan bahwa Komisi Yudisial merupakan lembaga negara yang bersifat mandiri dan berwenang mengusulkan pengangkatan hakim agung dan mempunyai wewenang lain dalam rangka menjaga dan menegakkan kehormatan, keluhuran martabat, serta perilaku hakim (Buku Saku Komisi Yudisial, Mengenal Lebih Dekat Komisi Yudisial.). Begitu pun dengan MK sejarah berdirinya lembaga Mahkamah Konstitusi (MK) diawali dengan diadopsinya ide MK (constitutional court) dalam amandemen konstitusi yang dilakukan oleh Majelis Permusyawaratan Rakyat (MPR) pada tahun 2001 sebagaimana dirumuskan dalam ketentuan Pasal 24 ayat (2), Pasal 24C, dan Pasal 7B Undang-Undang Dasar 1945 hasil Perubahan Ketiga yang disahkan pada 9 Nopember 2001. Ide pembentukan MK merupakan salah satu perkembangan pemikiran hukum dan kenegaraan modern yang muncul di abad ke-20 (melalui https://mkri.id/index.php?page=web.ProfilMK\&id=1).

Menurut Ni Kadek Riza Sartika Setiawati dan Nyoman Mas Aryani, latar belakang dibentuknya DPD adalah: (1) menguatkan ikatan daerah dalam bingkai Negara Indonesia serta memperteguh persatuan kebangsaaan di setiap daerah; (2) peningkatan akomodasi dan aspirasi dan kepentingan daerah dalam kebijakan nasional; (3) melaksanakan percepatan demokrasi, pembangunan, dan kemajuan daerah, dengan mengoptimalkankan peran dan fungsi utusan daerah yang awalnya merupakan fraksi dari lembaga MPR (Setiawati, Aryani, 2011, h. 3).

Sampai periode ke-III terbentuknya DPD ini, muncul pertanyaan mengenai eksistensi DPD. DPD dianggap tidak mempunyai kewenangan yang mengikat dalam kegiatan bernegara. Hal tersebut dapat dikaji dalam Pasal 22D ayat (1), ayat (2), dan ayat (3) UUD 1945 terkait kewenangan DPD. Hal tersebut berimplikasi pada ungkapan bahwa DPD hanya sebagai auxiliary terhadap fungsi DPR, padahal dasar isu pembentukan DPD pada pembahasan amandemen UUD 1945 adalah menjadikan DPD sebagai penyeimbang DPR dalam lembaga legislatif (Toding, 2017, h. 298).

DPD yang dilahirkan dari hasil amandemen ketiga tujuan dasarnya sebagai penyeimbang DPR dalam melaksanakan fungsi legislasi dibidang daerah dan otonom, tidak sesuai kenyataan dan harapan, karna pada faktanya dalam Undang-Undang Nomor 17 Tahun 2014 Tentang Majelis Permusyawaratan Rakyat, Dewan Perwakilan Rakyat, Dewan Perwakilan Daerah, dan 
Dewan Perwakilan Rakyat Daerah dalam Undang-Undang Nomor 12 Tahun 2011 tentang Pembentukan Peraturan Perundang-Undangan hanya diberi wewenang sebatas mengajukan, membahas, dan memberikan pertimbangan (Pasal 71 Undang-Undang Nomor 17 Tahun 2014 tentang Majelis Permusyawaratan Rakyat, Dewan Perwakilan Rakyat, Dewan Perwakilan Rakyat Daerah, dan Dewan Perwakilan Daerah) yang menurut penulis DPD dihadirkan pada masa amandemen ketiga UUD 1945 tidak mencerminkan cita-cita pembentukannya.

Pembentukan DPD sebagai bagian lembaga legislatif juga di akibatkan karena hasil pembahasan amandemen UUD 1945 menentukan tentang posisi dari MPR pasca reformasi tidak lagi berkedudukan sebagai lembaga tertinggi negara. Namun MPR menjadi Lembaga yang seimbang dengan kewenangan yang berbeda dan telah menjadi forum (join session) atau rumah bagi DPR dan DPD dalam sistem kamar pemerintahan, yang biasa disebut para ahli hukum sebagai suatu forum Bersama. Forum (bersama) ini mencerminkan sistem kekuasaan legislatif di Amerika Serikat dimana senate (DPD) dan house of representative (DPR) berkumpul untuk membentuk sebuah congress (MPR).

Kemudian dalam proses pembentukan undang-undang, DPD juga diberikan kewenangan membahas undang-undang tertentu dan memberikan pertimbangan kepada Dewan Perwakilan Rakyat atas rancangan undang-undang yang berkaitan dengan pajak, pendidikan dan agama (Putusan MK Nomor 92/PUU-X/2012). Jadi, terkait persetujuan RUU menjadi undang-undang, DPD tidak memiliki kewenangan tersebut. Ada beberapa pro dan kontra terkait frasa "membahas" dalam kewenangan DPD. Beberapa kalangan berpendapat bahwa DPD memiliki kewenangan untuk memberikan persetujuan karena akhir dari pembahasan adalah memberikan persetujuan atas RUU, atau dengan kata lain persetujuan masih masuk dalam substansi materi pembahasan.

Oleh karena itu, penulis beranggapan bahwa penelitian ini harus dilakukan mengingat memang fungsi DPD tidak sesuai dengan cita-cita pembentukannya dan tidak mencerminkan sistem checks and balances dalam peran, fungsi dan wewenangnya. Berkaitan dengan itu setelah dikeluarkannya Putusan Mahkamah Konstitusi Nomor 92/PUU-X/2012, memang harus dibahas lebih lanjut mengenai DPD dalam sistem ketatanegaraan Indonesia. Berdasarkan uraian diatas, maka penulis merumuskan permasalahan yaitu mengenai optimalisasi penguatan Dewan Perwakilan Daerah dalam sistem ketatanegaraan Indonesia Pasca Putusan MK Nomor 92/PUU$\mathrm{X} / 2012$.

\section{METODE PENELITIAN}

Sesuai dengan permasalahan yang diteliti, penelitian ini merupakan penelitian hukum (legal research). Istanto, mengatakan penelitian hukum adalah penelitian yang diterapkan atau diberlakukan khusus pada ilmu hukum (Istanto, 2007: 29). Sejalan dengan Istanto, Marzuki mengatakan penelitian hukum adalah suatu proses untuk menemukan aturan hukum, prinsipprinsip hukum, maupun doktrin-doktrin hukum guna menjawab isu-isu hukum yang dihadapi (Marzuki, 2005: 35).

Jenis penelitian yang digunakan dalam penulisan ini adalah penelitian pustaka (library research). Library research berarti penelitian yang menggunakan dokumen tertulis sebagai data, dan sumber data yang digunakan dalam penelitian ini mencakup bahan hukum primer, bahan hukum sekunder dan bahan tersier. Bahan hukum primer adalah bahan hukum yang mengikat atau yang membuat orang taat hukum, meliputi produk hukum yang menjadi bahan 
kajian dan produk hukum sebagai alat kritiknya. Bahan hukum sekunder meliputi penjelasan bahan hukum primer berupa doktrin para ahli yang ditemukan dalam buku, jurnal, dan dalam website

\section{PEMBAHASAN DAN ANALISIS \\ Teori Pembagian dan Pemisahan Kekuasaan}

Aristoteles dalam buku 'politics' menyatakan bahwa kekuasaan suatu negara dibagi menjadi 3 bagian. Pertama, kekuasan untuk mengadakan peraturan-peraturan berupa prinsipprinsip yang harus ditaati warga negara, yang disebut kekuasaan legislatif. Kedua, kekuasaan untuk melaksanakan peraturan-peraturan, yang disebut kekuasaan eksekutif. Ketiga, kekuasaan untuk menyatakan apakah anggota masyarakat bertingkah laku sesuai dengan peraturan legislatif; dan apakah dalam melaksanakan peraturan kekuasaan eksekutif tidak menyimpang dari prinsip-prinsip yang ada, yang disebut kekuasaan yudikatif (Gaffar, 2012, h. 109-110).

Pemikiran modern tentang pemisahan kekuasaan yang menjadi aturan organisasi negara demokrasi modern, dikemukakan Montesquieu. Kekuasaan dibagi menjadi 3 (trias politica), yaitu kekuasaan legislatif atau pembentuk undang-undang, kekuasaan eksekutif atau kekuasaan menjalankan undang-undang, dan kekuasaan yudikatif atau kekuasaan mengadili. Masingmasing kekuasaan harus dipisahkan dan dipegang oleh lembaga yang berbeda-beda. Apabila kekuasaan legislatif dan eksekutif disatukan pada tangan atau lembaga yang sama, maka tidak mungkin terdapat kemerdekaan karna pembuat hukum yang akan melaksanakan hukum tersebut akan memperbesar kekuasaannya sendiri. Apabila kekuasaan legislatif di gabungkan dengan kekuasaan yudikatif, maka kehidupan dan kemerdekaan warga negara akan dikuasai oleh pengawasan yang sewenang-wenang, karena hakim juga menjadi pembuat undangundang. Apabila kekuasaan yudikatif digabungkan dengan kekuasaan eksekutif, maka hakim akan bersikap dan bertindak dengan kekerasan dan penindasan (Gaffar, 2012, h. 109-110).

Sebelum adanya perubahan pada 1999 hingga 2002, UUD 1945 tidak menganut pemisahan kekuasaan (separation of power), tetapi menerapkan model lain, yang disebut oleh beberapa ahli hukum dengan istilah pembagian kekuasaan (distribution of power). Kekuasaan tidak dipisah-pisahkan menurut fungsi eksekutif, legislatif, dan yudikatif kepada lembaga yang berbeda-beda. Kekuasaan dibagi-bagi di antara lembaga-lembaga negara, dengan tumpuan kekuasaan utama adalah pada presiden. Presiden adalah pemegang kekuasaan pemerintahan tertinggi (eksekutif) sekaligus pemegang kekuasaan membentuk undang-undang, walaupun dalam pelaksanaannya terdapat peran DPR sebagai co-legislator. Di sisi lain, walaupun penjelasan UUD 1945 sebelum perubahan menyatakan bahwa kekuasaan kehakiman merupakan kekuasaan yang merdeka terlepas dari pengaruh kekusaan pemerintah, namun dalam praktiknya kekuasaan presiden dalam penentuan Hakim Agung dan ketua Mahkamah Agung sangat besar. Bahkan pada saat itu departemen kehakiman memiliki pengaruh yang besar terhadap kedudukan para hakim (Gaffar, 2012, h. 109-110). Tetapi tumbuh dan berkembang dalam kegiatan ekonomi Indonesia juga dipengaruhi oleh sistem yang berlaku (Ramadhani, 2019, h. 261-262).

Sistem pembagian kekuasaan tersebut melahirkan struktur kekusaan yang excecutive heavy dan berpotensi melahirkan pemerintahan otoritarian. Menyadarai hal tersebut, konstruksi kenegaraan yang dibangun melalui perubahan UUD 1945 pada 1999 hingga 2002 adalah menerapkan pemisahan kekuasan Checks and Balances. Antara kekusaan legislatif, eksekutif, 
dan yudikatif secara tegas dipisahkan dan dipegang oleh lembaga yang berbeda. Kekuasaan legislatif dipegang oleh DPR berdasarkan ketentuan Pasal 20 ayat (1) UUD 1945. Selain itu, walaupun tidak memiliki kekuasaan yang sama dengan DPR, dalam cabang kekuasaan legislatif juga terdapat DPD (Janedjri M. Gaffar, 2012, h. 111-112). Kekuasaan eksekutif dipegang oleh presiden berdasarkan pasal 4 ayat (1) UUD 1945. Sebagai pemegang kekuasaan eksekutif yang menjalankan Undang-undang, Presiden memiliki wewenang menetapkan peraturan pemerintah. Dalam menjalankan kekuasaan eksekutif, presiden dibantu oleh seorang wakil presiden serta mentri-mentri negara. Kekuasaan yudikatif, atau dalam UUD 1945 disebut sebagai kekuasaan kehakiman, adalah kekusaan yang merdeka untuk menyelenggarakan peradilan guna menegakkan hukum dan keadilan. Kekuasaan ini dilakukan oleh Mahkamah Agung dan badan peradilan yang berada dibawah nya, dan oleh sebuah Mahkamah Konstitusi (Gaffar, 2012, h. 113-114).

Andreyeni dalam Ida Hanifah memaparkan bahwa "Konstitusi di Indonesia sendiri telah menuangkan bahwa relasi antara negara dan warga negara sudah sangat jelas ada dan seharusnya menjadi pijakan hukum yang harus dilaksanakan oleh pemerintah sebagai sebuah kewajiban. Secara umum, kewajiban negara secara implisit ada di dalam Pembukaan UUD 1945 yakni pada alinea keempat yang menegaskan bahwa Negara berkewajiban untuk melindungi segenap bangsa Indonesia dan seluruh tumpah darah Indonesia, memajukan kesejahteraan umum, mencerdaskan kehidupan bangsa, dan melaksanakan ketertiban dunia yang berdasarkan kemerdekaan, perdamaian abadi, dan keadilan sosial" (Hanifah, 2020, h. 13).

Selain MA dan MK, dalam rumpun cabang kekuasaan kehakiman terdapat Lembaga Komisi Yudisial (KY). Komisi ini bukan merupakan pelaku kekuasaan kehakiman karena tidak memiliki wewenang menyelenggarakan peradilan (Janedjri M. Gaffar, 2012: 113-114). KY bersifat mandiri yang memiliki wewenang mengusulkan pengangkatan Hakim Agung serta wewenang lain dalam rangka menjaga dan menegakkan kehormatan, keluhuran martabat, serta perilaku hakim (Gaffar, 2012, h. 113-114).

\section{Optimalisasi Penguatan Dewan Perwakilan Daerah Dalam Sistem Ketatanegaraan Indonesia}

DPD dalam kurun waktu Oktober 2004 sampai dengan Oktober 2014 telah mengajukan 57 (lima puluh tujuh) RUU, 237 (dua ratus tiga puluh tujuh) Pandangan dan Pendapat, 74 (tujuh puluh empat) Pertimbangan dan 138 (seratus tiga puluh delapan) hasil pengawasan. Seluruh RUU tersebut telah disampaikan kepada DPR namun tidak semua ada tindak lanjutnya. Beberapa RUU tersebut telah menjadi undang- undang namun bukan merupakan merupakan RUU usul inisiatif DPD dan keterlibatan DPD dalam pembahasan RUU tersebut sangat terbatas, hanya RUU Kelautan yang menjadi usul inisiatif DPD dan akhirnya menjadi undangUndang yang pembahasannya dilakukan secara 3 (tiga) pihak (tripatrit) yaitu: DPR, Pemerintah dan DPD (Sekretariat Jenderal DPD RI, Profil Dewan Perwakilan Daerah Republik Indonesia Tahun Sidang 2014-2015).

Di dalam rangka mendudukan fungsi legislasi DPD sesuai dengan UUD 1945, pada tanggal 14 September 2012, DPD telah menyampaikan permohonan Pengujian Undang-Undang atas UU 27/2009 dan UU P3 terhadap UUD NRI 1945 kepada Mahkamah Konstitusi (MK) yang kemudian diregistrasi dalam nomor perkara 92/PUU-X/012. Permohonan uji materi dimaksud, 
dilakukan untuk memperoleh penafsiran yang lebih tepat dan pasti bagi kepentingan bersama dalam sistem legislasi antara DPR, DPD, dan Presiden. Melalui beberapa kali sidang, akhirnya pada hari Rabu tanggal 27 Maret 2013, pukul 15.20 WIB, MK memutus perkara tersebut, yang dimuat dalam Berita Negara Republik Indonesia Nomor 26 Tahun 2013. Dalam putusannya itu, MK telah menegaskan 5 (lima) hal keterlibatan DPD dalam proses legislasi, yaitu: (Putusan MKNomor 92/PUU-X/2012).

1. dalam mengajukan RUU yang berkaitan dengan daerah, DPD setara dengan DPR dan Presiden;

2. Hak/kewenangan DPD sama dengan DPR dan Presiden dalam membahas RUU;

3. DPD ikut membahas RUU tetapi tidak ikut memberi persetujuan terhadap RUU menjadi $\mathrm{UU}$;

4. DPD ikut menyusun Program Legislasi Nasional; dan

5. DPD memberikan pertimbangan tanpa ikut serta dalam pembahasan RUU. Dalam hal ini, DPR dan Presiden wajib untuk meminta pertimbangan DPD atas RUU APBN.

Jadi dapat disimpulkan bahwa kewenangan DPD terkiat proses pembentukan undangundang berdasarkan Pasal 22D ayat (1) dan ayat (2) UUD 1945 dan tafsiram Putusan MK melalui Putusan MK No. 92/PUU-X/2012 dan Putusan MK Nomor 79/PUU-XII/2014 adalah: 1. Mengajukan kepada RUU (bukan usul RUU) yang berkaitan dengan:
a. Otonomi daerah
b. Hubungan pusat dan daerah
c. Pembentukan dan pemekaran serta penggabungan daerah
d. Pengelolaan sumber daya alam dan sumber daya ekonomi lainnya
e. Serta yang berkaitan dengan perimbangan keuangan pusat dan daerah

2. Ikut membahas RUU yang berkaitan dengan:
a. Otonomi daerah
b. Hubungan pusat dan daerah
c. Pembentukan, pemekaran dan penggabungan daerah
d. Pengelolaan sumber daya alam dan sumber daya ekonomi lainnya
e. Perimbangan keuangan pusat dan daerah

3. Memberikan pertimbangan kepada DPR atas RUU terkait:
a. pajak
b. pendidikan
c. agama

Di dalam Putusan tersebut, Mahkamah Konstitusi dengan tegas menyatakan bahwa Pasal 102 ayat 1 huruf d, e dan h serta Pasal 147 Undang-Undang Nomor 27 Tahun 2009 bertentangan dengan Udang-Undang Dasar 1945 dan tidak mempunyai kekuatan hukum mengikat. Hal tersebut berarti setiap rancangan undang-undang yang diajukan oleh DPD tidak lagi melalui proses di Badan Legislasi melainkan diperlakukan setara dengan rancangan undang-undang yang diajukan oleh Presiden dan harus tetap dianggap sebagai rancangan undang-undang yang diajukan oleh DPD. Putusan ini dipandang mengembalikan jati diri DPD sebagai lembaga negara yang dalam legislasi kedudukannya setara dengan DPR dan Presiden (Anna Triningsih, 2010).

Komparasi dengan DPD masa kini, maka terjadi ketimpangan kewenangan dalam kamarkamar kekuasaan pemerintah khususnya antara DPR dan DPD. Putusan tersebut disambut 
gembira, terutama oleh DPD yang dalam proses legislasi selama ini dianggap sekedar menjadi bayang-bayang karena didudukkan inferior berada di bawah dominasi DPR. Inferioritas DPD dalam proses legislasi telah sejak lama menjadi sorotan, bahkan sejak awal-awal keberadaan DPD sendiri. Inferioritas DPD tersebut dianggap sebagai anomali dalam sistem bicameral Sebagaimana yang dipraktikkan dibanyak negara. Menyebut lemah dan tidak imbangnya posisi DPD dibandingkan DPR dalam proses legislasi tersebut, M. Fajrul Falakh menggolongkannya ke dalam asymetric bicameralism. Menurut Giovanni Sartori, asymmetric bicameralism atau weak bicameralism atau soft bicameralism menunjuk pada kondisi apabila kekuatan salah satu kamar jauh lebih dominan atas kamar lainnya (Sartori, 1997, h. 184).

Menurut Martiman Prodjohamidjojo, putusan yang telah memperoleh kekuatan mutlak itu mempunyai kekuatan hukum mengikat. Hal yang demikian, lebih dikenal dengan sebutan dalam bahasa latin 'resjudicata pro veritate habetur' yang artinya putusan yang pasti dengan sendirinya mempunyai kekuatan mengikat (Prodjohamidjojo, 2005). Lebih lanjut Martiman Prodjohamidjojo (2005) mengemukakan, suatu putusan pengadilan yang telah mempunyai kekuatan mutlak dapat dijalankan atau putusan tersebut mempunyai kekuatan eksekutorial (Zainuddin, 2019, h. 280).

Oleh karena itu, dalam penguatan fungsi legislasi pada DPD, penulis sepakat dengan adanya isu amandemen konstitusi yang di gagas Pan Muhammad Faiz dalam bukunya. Bagi yang menginginkan amandemen lanjutan, amandemen UUD 1945 seyogianya dilakukan dan dikampanyekan terlebih dahulu pada masa pemilu Presiden dan legislatif agar rakyat yang memiliki kedulatan benar-benar memahami dan memberikan persetujuan kepada perwakilan politisi mereka. Sebagian usulan amandemen kelima yang sering menjadi pembahas di tengahtengah akademisi dan masyrakat luas salah satunya pada table 4. Daftar sebagian usulan amandemen kelima UUD 1945 pada poin 4 yang isu amandemen tentang peran dan kewenangan Dewan Perwakilan Daerah (DPD) (Pan Mohammad Faiz, 2019, h. 99). Artinya Pan Muhammad faiz sejalan dengan pemikiran penulis dengan sistem legislasi DPD yang diperkuat.

DPD perlu diperkuat karena nafas pembentukan DPD itu sendiri yang memiliki nilai fundamental dalam kegiatan bernegara. Kedudukan DPD yang saat ini diparadigmakan sebagai lembaga legislatif memiliki tujuan yang sangat penting. Dalam teori struktur parlemen. Ada tiga prinsip perwakilan yang dikenal di dunia, yaitu: (Jimly Asshiddiqie, 2007).

1. Representasi politik (political representation)

2. Representasi territorial (territorial representation)

3. Representasi fungsional (functional representation)

Representasi politik yang berarti DPD harus bertanggung jawab atas legitimasi yang diberikan rakyat, fungsi dan wewenangnya harus sekuat legitimasinya. Begitu pula dengan representasi territorial yang DPD memang perwakilan daerah untuk 'Bertarung' dan 'Berjuang' demi kepentingan daerah, pasca amandemen ketiga Undang-Undang Dasar 1945 representasi fungsional tidak dipakai di Indonesia, karena fungsinya disamakan dengan DPR.

Kesadaran hukum masyarakat merupakan suatu penelitian terhadap apa yang dianggap sebagai hukum yang baik dan yang tidak baik. Penelitian terhadap hukum tersebut didasarkan pada tujuannya, yaitu apakah hukum tadi adil atau tidak, oleh karena keadilanlah yang diharapkan oleh warga masyarakat. Hampir semua masyarakat ingin hidup pantas yang secara implisit berarti suatu keteratuaran, misalnya pada kehidupan sehari-hari, masing-masing sudah 
mempunyai suatu urutan kegiatan-kegiatan yang tersusun dalam daftar yang tersimpan di dalam pikirannya (Faisal, 2018, h. 144).

Oleh karena itu untuk penguatan berikutnya, selain amandemen kelima UUD 1945, penulis juga berpendapat bahwa Dewan Perwakilan Rakyat selaku Lembaga legislatif pembuat undangundang yang telah disinggung diatas, harus merumuskan Undang-Undang Nomor 13 tahun 2019 tentang MPR, DPR, DPD dan DPRD dan Undang-Undang P3 terbaru yang di dalam undang-undang tersebut kewenangan Dewan Perwakilan Daerah harus dimuat dalam materi muatan undang-undang tersebut setara dengan Dewan Perwakilan Rakyat dan Presiden selaku Lembaga pembuat undang-undang, jadi Dewan Perwakilan Daerah telah menjadi Lembaga yang sesuai dengan yang di cita-citakan oleh amandemen ketiga tersebut.

\section{KESIMPULAN}

Pasca Putusan Mahkamah Konstitusi Nomor 92/PUU-X/2012 penulis berpendapat kewenangan DPD dalam fungsi legislasinya belum setara dengan DPR dan Presiden selaku lembaga pembuat Undang-Undang, Sehingga cita-cita dibentuknya DPD pasca amandemen ketiga belum terwujud sebagaimana mestinya, DPD masih saja dibawah bayang-bayang DPR dan Presiden dalam membentuk Undang-Undang. Maka dari itu, penulis berpendapat bahwa perlu amandemen lanjutan yaitu amandemen kelima untuk mempertegas kewenangan dan fungsi legislasi yang kuat sekuat cita-citanya atau DPR harus berani berbagi tugas dengan dengan DPD dalam Legislasi demi menggapai sistem checks and balances yang sesesunggahnya. Atau dengan cara lain yaitu, dengan dimasukkannya penguatan kewenangan DPD yang setara dengan DPR dan Presiden dalam hal membuat Undang-Undang dalam materi muatan Undang-Undang Pembentukan Peraturan Perundang-undangan dan Undang-Undang MD3 yang baru untuk terpenuhinya cita-cita dibentuknya DPD tersebut dan berjalannya dengan baik sistem checks and balances.

\section{SARAN}

Diharapkan dengan adanya amandemen mempertegas kewenangan dan fungsi legislasi yang kuat sekuat cita-citanya atau DPR harus berani berbagi tugas dengan dengan DPD dalam Legislasi demi menggapai sistem checks and balances yang sesesunggahnya. Atau dengan cara lain yaitu, dengan dimasukkannya penguatan kewenangan DPD yang setara dengan DPR dan Presiden dalam hal membuat Undang-Undang dalam materi muatan Undang-Undang Pembentukan Peraturan Perundang-undangan dan Undang-Undang MD3 yang baru untuk terpenuhinya cita-cita dibentuknya DPD tersebut dan berjalannya dengan baik sistem checks and balances. 


\section{DAFTAR PUSTAKA}

Asshiddiqie, Jimly. (2005). Konstitusi dan Konstitusionalime di Indonesia. Jakarta: Konstitusi Press.

. (2005). Sengketa Kewenangan Antarlembaga Negara. Jakarta: Konstitusi Press.

. (2006). Perkembangan dan Konsolidasi Lembaga Negara Pasca Reformasi. Jakarta: Sekertariat Jendral Mahkamah Konstitusi.

(2012). Hukum Acara Pengujian Undang-Undang. Jakarta; Sinar Grafika.

Diantha, I Made Pasek. (1990). Tiga Tipe Pokok Sistem Pemerintahan dalam Demokrasi Modern. Bandung: Abardin.

Fahmal, A. Muin. (2014). Konstitusionalitas DPD berdasarkan Pasal 22 D UUD NRI 1945 dan pada posisi DPD pada UU MD3 pasca-putusan MK. makalah disampaikan di Jakarta.

Faisal. (2018). Akibat Hukum Ketiadaan Akta Ikrar Wakaf Atas Perwakafan Tanah. De Lega Lata Jurnal Ilmu Hukum Fakultas Hukum Umsu. 3 (2). 143-153. https://doi.org/10.30596/dll.v3i2.3154.

Faiz, Pan Mohammad. (2019). Amandemen Konstitusi (Komparasi Negara Kesatuan dan Negara Federal). Depok: Rajawali Pers.

Gaffar, Janedjri M. (2012). Demokrasi Konstitusional praktik ketatanegaraan Indonesia setelah perubahan UUD 1945. Jakarta: Konstitusi Press.

Ghoffar, Abdul. (2009). Perbandingan Kekuasaan Presiden Indonesia Setelah Perubahan UUD 1945 dengan Delapan Negara Maju. Jakarta: Kencana Pranada Media Group.

Hadi, Sofyan. (2018). Fungsi legislasi dalam system presidensil (studi perbanadingan amerika serikat dan Indonesia). Vol. 9, No. 18. Februari 2018.

Hanifah, Ida. (2020). Peran Dan Tanggung Jawab Negara Dalam Perlindungan Hukum Tenaga Kerja Indonesia Yang Bermasalah Di Luar Negeri. De Lega Lata Jurnal Ilmu Hukum Fakultas Hukum Umsu. 5 (1). 10-23. https://doi.org/10.30596/dll.v5i1.3303.

Isra, Saldi. (2015). Pergeseran Fungsi Legislasi; Menguatnya Model Legislasi Parlementer dalam Sistem Presidensial Indonesia. Jakarta: PT. RajaGrafindo Persada.

Linrung, Tamsil. (2019). Penguatan DPD wujdukan DPD berdaya. Jakarta: Bibliosmia (Karya Indonesia).

Marzuki, Peter Mahmud. (2005). Penelitian Hukum. Jakarta: Kencana Prenada Media Group.

Patterson, Samuel., Anthony Mughan. (1999). Senates: bicameralism in the contemporary world. Ohio: State University Press.

Purba, Parlindungan. (2010). Kedudukan dan Fungsi Dewan Perwakilan Daerah (DPD) Dalam Sistem Ketatanegaraan Indonesia. Vol. 2. No. 2. Agustus 2010.

Putusan MK Nomor 92/PUU-X/2012.

Ramadhani, Rahmat., Ramlan. (2019). Perjanjian Build Operate And Transfer (BOT) Lapangan Merdeka Medan Dalam Pandangan Hukum Adminsitrasi Negara Dan Hukum Bisnis. 4 (2). 255-270. https://doi.org/10.30596/dll.v4i2.3182. 
Sartori, Giovanni. Comparative Constitutional Engineering: An Inquiry into Structures, Incentives and Outcomes, New York: New York University Press.

Sekretariat Jenderal DPD RI, 2014-2015 .Profil Dewan Perwakilan Daerah Republik Indonesia Tahun Sidang. Jakarta: Sekretariat Jenderal DPD RI

Sekretariat Jenderal MPR dengan UNDP 2003, "Dewan Perwakilan Daerah dalam system ketatanegaraan republic Indonesia”. Jakarta:secretariat jenderal MPR

Setiawati, Ni Kadek Riza Sartika., Nyoman Mas Aryani. (2011). Kewenangan DPD Dalam Sistem Ketatanegaraan Indonesia Pasca Putusan Mahkamah Konstitusi, Fakultas Hukum Universitas Udayana, Denpasar.

Strong, CF. (1975). Modern Political Constitution;An Introduction to The Comparative Study of Their History and Existing Form. London: Sidwick\&Jackson Limited.

Tanpa nama, MK Tegaskan Kewenangan Legislasi DPD. Diakses melalui https://www.hukumonline.com/berita/baca/lt5601bbd20ced6/mk-tegaskankewenangan-legislasi-dpd

Toding, Adventus. (2017). DPD Dalam Struktur Parlemen Indonesia: Wacana Pemusnahan versus pengutan. Jurnal Konstitusi, Vol. 14. No. 2.

Triningsih, Anna. (2010). Politik Hukum kewenangan konstitusional Dewan Perwakilan Daerah dalam Proses legisla pasca Putusan MK Nomor 92/PUU-X/2012. RechtsVinding. Vol. 2., No. 2.

Undang-Undang Dasar Negara Republik Indonesia Tahun 1945

Wahidin, Samsul. (2014). Distribusi kekuasaan negara Indonesia. Yogyakarta: Pustaka Pelajar.

Zainuddin. (2019). Eksekusi Terhadap Pembatalan Surat Izin Mendirikan Bangunan Pada Perkara Tata Usaha Negara. De Lega Lata Jurnal Ilmu Hukum Fakultas Hukum Umsu. 4(2). 271-288. Https://Doi.Org/10.30596/D1l.V4i2.3198. 